\title{
High Quality Human Resources with Divergent Multicultural Exposure's Epistemic Beliefs and Proficiency
}

\author{
I Emaliana $^{1}$, M Galkina ${ }^{2}$, N B Fauzi ${ }^{3}$, E Junining ${ }^{4}$, D Hartono ${ }^{5}$ \\ $1,3,4,5$ Universitas Brawijaya, Malang, Indonesia \\ ${ }^{2}$ Vyatka State University, Kirov, Russia \\ \{1ive@ub.ac.id, ${ }^{2}$ galkinamo@yandex.ru, ${ }^{3}$ banyubening@ub.ac.id, ${ }^{4}$ esti@ub.ac.id, \\ ${ }^{5}$ didik_htono@yahoo.com\}
}

\begin{abstract}
This research examines the correlation between EFL students' epistemic beliefs, the way they define learning and how they learn English, and English proficiency to predict human resources' quality with divergent multicultural exposure. Test of English as a Foreign language (TOEFL) is chosen to represent English proficiency, mandatory for more than $90 \%$ of job posts in Indonesia. The higher level of epistemic beliefs should predict the high scores of TOEFL. This paper is aimed at analyzing and introduce the concept of epistemic beliefs and the planning of high quality human resources at University level, and is an effort to reflect on the importance of epistemic beliefs for formulating learning outcomes for English department. Major findings indicate epistemic beliefs are prominent grounds under the development of classroom level curriculum, as students are exposed with various multicultural background. This paper presents recommendations for curriculum reference and teaching instructions, teacher education and further studies.
\end{abstract}

Keywords: EFL, EFL epistemic beliefs, TOEFL, Human resources, Multiculture

\section{INTRODUCTION}

In Indonesia and many other Asian countries, internationalization plays a prominent role for higher education institutes (HEI)s. Because this run has become gradually noteworthy, international students are accepted by many HEIs, causing various cultural diversities on campus. For instance, based on 2017 census reported by Indonesian higher education institute supervisior [1], international students with total 6,967 were pursuing for degree, non-degree or other college programs. This number is surging for 100 to 500 weekly. These students were coming from over 10 countries; mostly they come from Timor Leste (33\%), Malaysia (16\%), and Thailand $(10 \%)$. Besides, Indonesia has over 300 ethnic groups, although their classification is not rigorous and in some cases unsettled because of migrations, cultural and linguistic influences among ethnics. Therefore, through the elevating of international students number as well as Indonesian students who are coming from various ethnic groups background pursuing higher education in Indonesia, Indonesian HEIs are inevitably growing more ethnically diverse and culturally rich yearly.

Besides, those divergent multicultural exposes identify students' characteristics in learning who are becoming future high quality human resources. These happen because specialized knowledge, social responsibility, autonomy of practice, and commitment for doing duty assignment are influenced by students' identity development which are much affected by 
divergent multicultural exposures possessed by each student [2]. Nowadays, pivotal strategic resource company is the consciously acquired, created and disseminated through a variety of methods knowledge which pinpointed on the establishment of appropriate characteristics of employees [3], besides promoting processes of information technology development. High quality human resources involve a high degree of responsibility and accountability upon community and individuals because they take place in employees' daily work activities aspects [4]. Therefore, since it is crucial for future high quality human resources, [3] propounds that it is foremost that initial academic background should cover professional identity components. Accordingly, recognizing that multicultural diversity and those pedagogical concerns are necessary, but insufficient, HEIs should integrate these into academic life.

Since universities in Indonesia recently have been growing in multicultural diversity, number of university faculties and administrators show a more distinguished enthusiasm to advance students' capability to work and interact with various cultural backgrounds people. These multicultural diversity acknowledgement has been perceived in numerous HEIs attempts to combine multicultural education to their campus activities and curricular. According to [5] and [6] English language curriculum should establish approach to nurture students' divergent multicultural competence, since multicultural education concept is vigorously linked to English language education. Despite fusing multicultural education in English language curriculum, HEIs responsibility in establishing students' multicultural competence, obtrudes considerable obstacles to Indonesian English language teachers, in which English is studied as a foreign language (EFL).

In EFL teaching and learning in universities, one way to measure students' competence in mastering English is by knowing students' English proficiency, besides achievement. Perceiving students' English proficiency scores means consequentially noticing the degree of the students' learning progress, which demonstrates how students define and construct knowledge succesfully. Since these beliefs affect students to control and utilize knowledge in the process of learning English, they play significant roles for students' thinking [7]. Those beliefs are enumerated to knowledge conceptualization and knowing process, notably, epistemic beliefs.

In addition, students who are learning EFL holds different beliefs about how it is learned. Among the various features, personal epistemic beliefs, elucidated as students' perspective about the nature of knowledge and knowing, has been presented to be relevant [8] [9]. Those beliefs are affceted by students' previous negative or positive experiences as language learners [8], family or home background [8], individual differences such as personality [7], and students' divergent cultural background [10] [11] [12]. These differences too are formed by beliefs which are connected to conceptualization of knowledge as well as process of knowing, namely epistemic beliefs.

Accordingly, EFL epistemic beliefs are closely related to English proficiency, like TOEFL, for having proficient English is a paramount significance for university students who demand high quality human reseources. Therefore, development of EFL proficiency is a pivotal element to students' mastery of language skills and intercultural learning [13]. It is a measure of skill which students can utilize English, for instance how proficient students to understand passages or comprehend oral infromation and also to perceive different cultures. In addition, EFL proficiency depicts students' cognitive ability, which associates to thinking performance [7]. Thus, encouraging the establishment of EFL proficiency for students in specific confirms students' competence which predict better performance as human resources.

Although students' personal characteristics like divergent multicultural exposures and epistemic beliefs determine potential human resources, supplementary cognitive capabilities 
such as English proficiency may be needed to support high quality human resources. Decades of accumulated evidence in human resources literature does suggest that high quality human resources only focuses on prerequisites before applying job, yet, it can be developed integratedly in university curriculum. Thus, using a framework of EFL epistemic beliefs, divergent multicultural backdrops, and English proficiency, intercultural competence curriculum such as the one discussed in this study can help guide the efforts in ensuring a more comprehensive integrated approach to high quality human resources. Accordingly, this study is aimed at revealing prediction about appropriate teaching techniques rooted from students' EFL epistemic beliefs and proficiency to have high quality human resources characteristics when they are exposed to divergent multicultural environment.

\subsection{Research Method}

This study established correlation between students with divergent multicultural backgrounds' EFL epistemic beliefs and proficiency. The findings of this research is pivotal for appropriate institutional, program, and students learning outcomes. It is advatageous for teachers to select effective teaching approach, techniques, materials and media. The present study was associative-descriptive research, for it aims to examine research problems as generated by previous research and test specific research hypothesis and relationship. Utilizing this method, some information can be planned structurally, systematically, and clearly. The researchers use a hypothesis, namely, the higher the students' level on EFL epistemic beliefs, the better their proficiency in English.

The participants of this research were 68 out of 70 English department students who volunteered in academic year 2018/2019. The instruments were epistemic beliefs questionnaire and TOEFL scores. The EFL epistemic beliefs questionnaire had 39 items, only items which showed obtained coefficient less than .05 were claimed valid, and measured through SPPS 20 to establish validity and reliability. The second instrument was English proficiency which was indicated from students' TOEFL scores.

There were some procedures carried out for the present research. Firstly, the questionaire was filled in by 70 students, but 68 among them were included as research data because of completeness responses consideration upon the questionnaire which was conducted in two different classes of English language education study programs. Due to the lecturers' convinience, each took ten minutes prior to the classes end. Research consent form agreements were distributed to the participants so they were sure that participating this research was not part of class requirements and no additional credit for them. Secondly, students' TOEFL scores were taken from the academic records with permission letter were used to measure their English proficiency. The scores were taken from paper and pencil TOEFL, administered by the faculty in 2018 which coved listening, reading, and grammar tests.

For data processing, dependent sample t-test using Pearson product moment was run by using SPSS software 20. In relation to correlation coefficients, a figure between 0.99-0.60 represents high correlation, meanwhile a figure between $0.59-0.30$ reflects moderate correlation, and 0.29-0.01 shows low correlation. [14] adds the correlation value is considered significant if it shows coefficient below 0.05 or unless not significant, if the significance value is exceed 0.05 . 


\subsection{Results and Discussion}

Table 1. Pearson Product Moment Correlation

\begin{tabular}{lccc}
\hline Relationship & $\begin{array}{c}\text { Sig. }(2- \\
\text { tailed })\end{array}$ & p-value & Interpretation \\
\hline $\begin{array}{l}\text { sophisticated epistemic } \\
\text { beliefs }\end{array}$ & 0.02 & -0.452 & significant, negative moderate \\
simple epistemic beliefs & .132 & -0.316 & not significant \\
\hline
\end{tabular}

The relationship between EFL epistemic beliefs and English language proficiency in this study is described as follow. Since the exact probability that the correlation due to the sampling error is 0.02 which is lower than the significance level 0.05 set by the researcher, the null hypothesis is rejected. It means there is an evidence to support the relationship between EFL epistemic beliefs and English language proficiency. Based on the coefficient obtained (0.452), the correlation is negative and moderate for students with sophisticated epistemic beliefs. This means the more sophisticated the students' EFL epistemic beliefs, there is a tendency the lower their English language proficiency. However, the results revealed that students with simple EFL epistemic beliefs are not significant in this study.

In relation EFL epistemic beliefs are found to be related to EFL proficiency. Particularly, EFL epistemic beliefs have negatively moderate correlations to listening, writing, reading, and speaking skills. The following discussion addresses each of predictions which follow the results, namely, the more sophisticated their EFL epistemic beliefs, it appears that the lower their English language proficiency. Results of the present investigation unravel different perspective on that previous studies related to sophistication of epistemic beliefs in science education [15] [10] [12] [11] [16], or sophistication of epistemic beliefs in relation to reading and literacy [9] [17] predict proficiently better students. Therefore, the present study results are inconsistent with the general trend, that more epistemologically sophisticated students usually outperform students with simple epistemic beliefs.

In this current research, sophisticated degree of EFL epistemic beliefs students stance had a poorer English proficiency. This finding is in sharp contrast to the results revealed in the previous study which examined relationship between epistemic beliefs and proficiency in English language learning [18]. It was demonstrated that sophisticated students (students who possesed high level of epistemic beliefs) had better English proficiency. However, the current research shows that simplicity of students' epistemic beliefs stance, as grounded by EFL model of epistemic beliefs, is closely related to increasing in their EFL proficiency context. In breadth, this result is in line with [19]'s finding that students who had significantly better performance for Internet based grammar achievement, reflects less sophisticated epistemological beliefs.

It appears that grammar becomes the focus of the proficient students. In this present study, the accuracy in using English language plays pivotal role to determine successful learning English. However, test anxiety can be one of the rooted problem of language anxiety [20] which can cause the low accuracy in English language learning. The test anxiety creates personal feeling of tension, apprehension, nervousness, and worry associates with an arousal of the automatic nervous system [21]. Therefore, creating anxiety-reducing strategies, including getting familiar with the test format can reduce both language anxiety and test anxiety, which can promote high proficiency English language.

Studies on epistemic beliefs generally shows the importance and relevance to learning patterns and proficiency, albeit distinct results are obtained in relation to epistemic beliefs 
development and their relationship to learning success. This is supported by [22] which reported that students' epistemic beliefs degrees are various, as they are formed by divergent cultural classifications. For instance, this is justifiable in Indonesian context, as Indonesian education culture and values are highly affected by concept that students are obliged to respects their instructors, for they are authorities who give explanation or correct answers, and students are discouraged to challenge their answers.

Three pedagogical implications which relate to educational phycology are proposed for preparing high quality human resources with divergent multuculture expose. First, findings of the present research can be used as foundations to develop course profile of listening, reading, and grammar in the English language program curriculum. It shows that in order to obtain high English proficiency, students' way of defining learning English language and how they should learn English can be encouraged through course description which are derived and generate from the results of this study. Secondly, this study emphasizes that communicative approach that is used as the basis of teaching and learning English for English department students require more emphasizes on grammar and translation approach. Notably, in the teaching of speaking, accuracy should obtain specific place to learn.

Thirdly, based on the present study, it appears that students with lower order of thinking outperform students with higher order of thinking, thus, several teaching strategies can be offered to accommodate the successful English language proficiency to students with sophisticated EFL epistemic beliefs. Several teaching and learning methods which can provide meaningful learning process to get better English proficiency for students with higher order of thinking are as follow. Firstly, students centered learning. This leads the higher order of learning students to get more meaningful activities. Secondly, cooperative learning method should be employed because this provides activities that make the students with simple and sophisticated EFL epistemic beliefs mingle when doing the learning processes. Thirdly, taskbased instruction can be applied when teaching English because this learning process facilitate higher order of thinking students who need to experience more challenging but in control learning procedures, this way, they are challenged to experience inductive learning or learning by implementing scientific approach.

\section{CONCLUSIONS}

Two main conclusions can be drawn for preparing teaching material for students where are exposed with divergent multiculture in order to make them high quality human resources. Firstly, students with high degree of EFL Epistemic beliefs also have low level of English language proficiency (scores in listening and reading). Secondly, regarding the EFL skills to teach, the communicative approach is still preferable, however, in addition to communicative approach, grammar translation method can be also be used in order to maintain the meaning to be comprehended as well as to conveyed. Particularly, in this study, in the teaching of speaking, the accuracy is seen as something important to maintain so that it can reduce the communication gap. Accuracy should be maintained well in the implementation of the teaching of speaking to make students be comfortable when they convey ideas without too much direct feedback given.

Two recommendations are suggested. First, it is suggested that EFL lecturers give more emphasis and practices in the form of in-class and out-class activities that lead the students to having more simple epistemic beliefs in general. Second, several research ideas like reexamining the EFL epistemic belief constructs and qualitative exploration. 


\section{REFERENCES}

[1] "Perguruan Tinggi Indonesia Diminati Mahasiswa Asing," 2017.

[2] C. Parkes and A. J. Davis, "Ethics and social responsibility - do HR professionals have the 'courage to challenge' or are they set to be permanent 'bystanders?," Int. J. Hum. Resour. Manag., vol. 24, no. 12, pp. 2411-2434, Jun. 2013.

[3] A. Ibănescu, "How Do Novice Specialists in Human Resources Develop their Professional Identity?," Procedia - Soc. Behav. Sci., vol. 187, pp. 596-600, May 2015.

[4] T. D. Solbrekke and T. Englund, "Bringing professional responsibility back in," Stud. High. Educ., vol. 36, no. 7, pp. 847-861, Nov. 2011.

[5] Manning, L. M., \& Baruth, L. G, Multicultural education of children and adolescents, 5th ed. Boston: Pearson, 2009.

[6] Y.-J. Lin and H.-C. Wang, "Using enhanced OER videos to facilitate English L2 learners' multicultural competence," Comput. Educ., vol. 125, pp. 74-85, Oct. 2018.

[7] N.-M. Chan, I. T. Ho, and K. Y. L. Ku, "Epistemic beliefs and critical thinking of Chinese students," Learn. Individ. Differ., vol. 21, no. 1, pp. 67-77, Feb. 2011.

[8] J. T. E. Richardson, "Epistemological development in higher education," Educ. Res. Rev., vol. 9, pp. 191-206, Jun. 2013.

[9] L. E. Ferguson and I. Bråten, "Student profiles of knowledge and epistemic beliefs: Changes and relations to multiple-text comprehension," Learn. Instr., vol. 25, pp. 49-61, Jun. 2013.

[10] J. A. Chen, "Implicit theories, epistemic beliefs, and science motivation: A personcentered approach," Learn. Individ. Differ., vol. 22, no. 6, pp. 724-735, Dec. 2012.

[11] T. Fujiwara, P. Laulathaphol, and B. J. Phillips, "Thai University Students' Scientific Epistemic Beliefs: Relationships with Past Learning Experiences," Procedia - Soc. Behav. Sci., vol. 69, pp. 187-196, Dec. 2012.

[12] G. M. Franco, K. R. Muis, P. Kendeou, J. Ranellucci, L. Sampasivam, and X. Wang, "Examining the influences of epistemic beliefs and knowledge representations on cognitive processing and conceptual change when learning physics," Learn. Instr., vol. 22, no. 1, pp. 62-77, Feb. 2012.

[13] Z. Tavakkoli, F. Rakhshandehroo, M. A. Izadpanah, and M. Moradi-Shad, "Ego Identity Types and Language Proficiency of Iranian EFL Learners," Procedia - Soc. Behav. Sci., vol. 98, pp. 1885-1894, May 2014.

[14] Butler, C.S., Statistics in Linguistics. Oxford: Basil Blackwell.

[15] C. Tsai, "Conceptions of learning science among high school students in Taiwan: a phenomenographic analysis," Int. J. Sci. Educ., vol. 26, no. 14, pp. 1733-1750, Nov. 2004.

[16] L. Mason, N. Ariasi, and A. Boldrin, "Epistemic beliefs in action: Spontaneous reflections about knowledge and knowing during online information searching and their influence on learning," Learn. Instr., vol. 21, no. 1, pp. 137-151, Feb. 2011.

[17] L. E. Ferguson, I. Bråten, H. I. Strømsø, and Ø. Anmarkrud, "Epistemic beliefs and comprehension in the context of reading multiple documents: Examining the role of conflict," Int. J. Educ. Res., vol. 62, pp. 100-114, 2013.

[18] Akbari, R. and Karimi, M.N, "EFL Students' Proficiency Outcomes: What do Epistemological Beliefs Have to Offer?," Asian EFL J. Q., vol. 15, no. 3.

[19] M. N. Karimi, "EFL students' grammar achievement in a hypermedia context: Exploring the role of Internet-specific personal epistemology," System, vol. 42, pp. 1-11, Feb. 2014. 
[20] Q. Huang, "Study on Correlation of Foreign Language Anxiety and English Reading Anxiety," Theory Pract. Lang. Stud., vol. 2, no. 7, Jul. 2012.

[21] M. Salehi and F. Marefat, "The Effects of Foreign Language Anxiety and Test Anxiety on Foreign Language Test Performance," Theory Pract. Lang. Stud., vol. 4, no. 5, May 2014.

[22] M. Sulimma, "Relations between epistemological beliefs and culture classifications," Multicult. Educ. Technol. J., vol. 3, no. 1, pp. 74-89, Apr. 2009. 